\title{
ACCESS TO UNCOMBINED TITANIUM THROUGH AN INHIBITING FILM IN SUBLIMATION PUMPING OF DEUTERIUM
}

by Robert Steinberg and Donald L. Alger

Lewis Research Center

Cleveland, Ohio

TECHNICAL PAPER proposed for presentation at the 19th National Vacuum Symposium of the American Vacuum Society Chicago, Illinois, October 2-5, 1972 
ACCESS TO UNCOMBIINED TITANIUM THROUGH AN INHIBITING FILM

IN SUBLIMATION PUMPING OF DEUTERIUM

by Robert Steinberg and Donald L. Alger

\author{
National Aeronautics and Space Administration \\ Lewis Research Center \\ Cleveland, Ohio
}

\title{
ABSTRACT
}

In principle, titanium bulk sublimator pumping should be ideal for removing large quantities of deuterfum from a vacuum system. In practice, much of the deposited titanium remains uncombined and is wasted. We have demonstrated, through a series of experiments, that it is possible (by the addition of a thin layer of títanium to an apparently occluded surface) to gain access to previously deposited sublayers of uncombined titanium in spite of the presence of an inhibiting film (such as an oxide) on the qurface. 


\section{INTRODUCTION}

Titanium bulk sublimator (TBS) pumping has found application in many different types of vacuum systems; however, it only recently has been considered for use in small neutron generators where sublimation pumping offers major advantages in reducing the tritium hazard and increasing system reliability (ref. 1). Tritium is radioactive and decays by beta emission, with a half-1ife of 12 years. More efficient use of the available titanium would provide extended pump life, thus further reducing the necessity of handling tritiated components.

Un1ike getter ion pumps, the pumping speed of a TBS is independent of pressure in the low-pressure ranges. As a result, control of the sublimation rate becomes an important consideration. This is normally a manual operation and a considarable amount of titanium is usually wasted. During the operation of our 300-kilovolt positiveion accelerator incorporating sublimation pumping, we became aware of the fact that it was possible, under certain circumstances, to gain access to previously-deposited uncombined sublayers of titanium. This ability to penetrate the inhibiting surface film could allow us to utilize the available titanium more efficiently; however, it may also have significance in other applications such as hydrogen pumping with sputter ion pumps and improved loading for tritiated neutron-generator targets.

This paper describes a set of experiments which was conducted in order to obtain a better understanding of the phenomenon observed and to attempt to determine the mechanism involved. 


\section{ADSORPTION OF DEUTERIUM BY TITANIUM}

Several processes take place during the interaction of deuterium with titanium: physical adsorption on the surface, activated adsorption, diffusion, absorption, and chemical interaction through the formation of chemical compounds. Our primary concern here is with physical adsorption which depends mainly on the state of the titanium surface. We know that this process occurs very rapldly until a monomolecular layer of the gas has been adsorbed on the surface. At this stage the gas molecules have not yet dissociated into atoms (ref. 2).

Physical adsoprtion is just the first phase in the total sorption process of deuterium in titanium and is followed by activated adsorption which is a much slower process and requires considerable time for the establishment of an equilibrium condition. Until now, it had been assumed that in activated adsorption the gas molecules dissociate into atoms which facilitate the diffusion of deuterium into the bulk titanium. Recently, this assumption that deuterium does diffuse into metals in the atomic and not the molecular form was experimentally confirmed (ref. 3 ). Moreover, it has been established that the deuterium also ionizes and diffuses rapidly as a deuteron (ref. 4). The condition of the surface has a considerable effect on the rate of diffusion. If both physical and activated adsorption are reduced, then the dissociation of molecules into atoms and, therefore, the diffusion of deucerium into titanium will also be limited. We know that the rate of diffusion decreases sharply in the presence of an oxide (ref.5). Under such conditions, the rate of diffusion is independent of the deuterium pressure and 
is determined solely by the condition of the oxide film on the surface.

If the inhibiting film is strictly a surface phenomenon, then the process of physical adsorption could be the controlling factor in restricting access to bulk titanium. Although we do not know the nature of this inhibiting film formed in the sublimator system nor its depth nor the extent to which it covers the titanium, we have made the following assumptions: (1) The inhibiting film is very thin; and (2) it does not completely cover the titanium surface. Based on these assumptions, if the processes of physical and activated adsorption could be initiated, thus enhancing the formation of deuterons, it seemed reasonable to expect that diffusion through the surface film could be increased. This hypothesis' could easily be verified by depositing a thin layer of titanium onto a surface which (1) had many previously deposited layers of uncombined titanium and (2) had reduced pumping speed due to an inhibiting film on the surface. APPARATUS

The accelerator system used for the measurements is described elsewhere and, therefore, will only be briefly mentioned here (ref. 6). Figure I shows the vacuum system of the 300-kilovolt 15-milliampere ion accelerator which served as a vacuum chamber for the measurements. Roughing down the system is accomplished with the aid of three sorption pumps. The TBS consists of a 400-gram rod of titanium which is heated by electron bombardment to approximate $1 y=1500^{\circ} \mathrm{C}$, causing the titanium to sublime onto the surface of a water-cooled chamber surrounding the 
rod. The fresh titanium forms stable solld compounds with the chemicallyactive gas molecules that strike the surface, resulting in high pumping speeds for active gases such as oxygen, hydrogen, nitrogen and water vapor. The inert-gas load and the hydrocarbons are pumped by a 2701iter/ago aputtox ion pump. The ayotem base pressure lo approximately $2 \times 10^{-8}$ torr. As vacuum systems go, the accelerator system 18 falrly "dirty." It lo not designed for bakeout; it has a large ceramic surface exposed to the vacuum (the high voltage section is $56 \mathrm{~cm} \mathrm{in}$ length by $53 \mathrm{~cm}$ in diameter) and uses vinyl seals for the high-voltage section and the source. Al1 measurements were made within this system. The deuterium gas leak for all measurements was restricted to 27 atm $\mathrm{cm}^{3} / \mathrm{hr}^{*}$ which is the flow rate required to maintain a 15 -milliampere beam of deuterons on target, and the pressure range of interest was limited between $2 \times 10^{-8}$ and $1 \times 10^{-5}$ torr which is the normal operating range. The sublimator was set to sublime at $1.0 \mathrm{grams} / \mathrm{hr}$ * EXPERIMENT I

In order to determine if we could penetrate the inhibiting surface film, the following experiment was performed. With the system at an equilibrium pressure of $6.5 \times 10^{-7}$ torr (See fig. 2.); deuterium gas with a leak rate of $27 \mathrm{~atm} \mathrm{~cm}^{3} / \mathrm{hr}$ was introduced into the system. The broadened lines in figure 2 indicate when deuterium gas is flowing. In less than 3 minutes, the system pressure had passed $1 \times 10^{-5}$ torr. The deuterlum leak was then closed and the TBS turned on for 0.5 . minutes to deposit 0.008 grams of titanium on the sublimation surface. 
After 20 minutes, the system reached an equilibrium pressure of approximate $1 . y 4 \times 10^{-7}$ torr. Deuterium gas was again introduced and the prenumre asain rous raplaly. However, at approximately $9 \times 10^{-6}$ ' torr, thr: ratee at which the pressure rose showed a marked decrease, nnd presumro then hold constant at approximately $1 \times 10^{-5}$ torr for 110 minutes. At this point in time, unfortunately, a low-flow safety switch on the accelerator heat exchanger shut the system down, cutting off the deuterium gas. Instead of re-establishing the gas leak, we elected to sublime again, only this time for 5 minutes depositing 0.08 grams of titanium. After the system reached a base pressure of approximately $1 \times 10^{-7}$ torr, we again introduced deuterium. The leak was maintained for 1578 minutes before a pressure of approximately $1 \times 10^{-5}$ torr was reached, after which the experiment was terminated. Based on a sublimation rate of $1 \mathrm{gram} / \mathrm{h}$, a deuterium flow rate of $27 \mathrm{~atm} \mathrm{~cm}^{3} / \mathrm{hr}$, and the formation of titanium deuteride (TiD ${ }_{1.5}$ ), * a total of 5.5 minutes of sublimed titanium should have been completely used up in about 73 minutes. The ability to pump a volume of gas significantly larger than could be consumed in the freshly deposited layer tends to confirm that the inhibiting film can be penetrated. EXPERIMENT II

In order to try to determine the dominant limiting process, the following experiment was conducted. As in the previous case, a deuterium gas leak of $27 \mathrm{~atm} \mathrm{~cm}^{3} / \mathrm{hr}$ was established. Figure 3 shows the rise in pressure with time. In 13 minutes the pressure rose 
from $4.1 \times 10^{-8}$ to $1 \times 10^{-6}$ torr (figure 3, curve $\equiv_{1}$ ). A layer of titanium was then sublimed onto the substrate for 5 minutes (0.08 grams). The system was allowed to establish an equilibirium pressure of $2.5 \times 10^{-8}$ torr and deuterium was again introduced (figure 3 , curve 非). A system pressure of $1 \times 10^{-6}$ torr was reached in 426 minutes. In this case, the 300 seconds of sublimed titanium should have been consumed in 67 minutes. Curves $\# 3$, \#4, and 非 represent repeats of the sequence used for curve 非 except no titanium was sublimed. (A period of 11 hours elapsed between the end of measurements for curve' 非 and the beginning of measurements for curve 非.) In each case an equilibrium pressure was established before another run was begun. Finally, titanium was sublimed for an additional 300 seconds $(0.08$ grams) and then the pressure change with time for the standard deuterium gas leak was again measured (See curve 非.). EXPERIMENT III

In order to determine if the 300-second sublimation time was sufficient to cover the entire sublimation chamber, it was decided to increase the sublimation time. The results of 7 separate runs are shown in figure 4. As was the case in previous runs, deuterium was leaked into the system at $27 \mathrm{~atm} \mathrm{~cm}^{3} / \mathrm{hr}$. The pressure rose from $3 \times 10^{-7}$ to $5 \times 10^{-6}$ torr in 52 minutes (curve $\equiv_{1}$ ). The leak was closed off allowing the system to come to equilibrium, and then a 5-minute deposit of titanium ( 0.08 grams) was placed on the substrate and the process repeated (curve 非). Figure 4 shows additional curves generated with sublimation times of $15,30,60,60$ and 5 minutes (curves 非-7). 
These results, obtained sequentially in one continuous time period lasting over 80 hours, are compared with calculated values and presented in Table $I$.

EXPERIMINTI IV

If: Indeed it was the oxygen which is responsible for the formation of the deuterium inhibiting film, it should be possible to form a deuterium barrier by introducing oxygen to the system and then perhaps to penetrate the barrier by means of an added layer of titanium. The results of experiment IV shown in figure 5 represent an attempt to produce and to penetrate such a barrier. The system was initially at an equilibrium pressure of $2 \times 10^{-7}$ torr. Titanium was then sub1 imed onto the chamber wall for 60 minutes ( 1 gram) in order to build up a thick layer of titanium. After equilibrium pressure was again established, high-purity oxygen was admitted to the system in order to form a barrier. The pressure was allowed to rise to approximately $10^{-4}$ torr and then the oxygen leak was closed. (The ion pump was only cracked open to the system in order to reduce its effect on this operation.) This procedure was repeated about 15 times during a 30-minute time interval in order to form a complete barrier to deuterium. Each time the deposited titanium pumped the oxygen introduced into the system. Deuterium gas was then leaked into the system ( $27 \mathrm{~atm} \mathrm{~cm}^{3} / \mathrm{hr}$ - See broadened line, figure 5.) resulting in the pressure reaching $5 \times 10^{-6}$ torr in 2 minutes; the barrier was effective. After subliming for 5 minutes (0.08 grams) and re-cstablishing an equilibrium pressure, 150 minutes were required for the pressure to reach $5 \times 10^{-6}$ torr.with the deuterium gas leak 
open. Once again titanium was sublimed for 5 minutes and, after establising a pressure equilibration at $6 \times 10^{-8}$ corr, deutorium was again admitted to the chamber; 375 minutes were required to reach $5 \times 10^{-6}$ torr. In theory 0.16 grams of titanium ( 10 minutes of subliming) should have removed about $60 \mathrm{~atm} \mathrm{~cm}^{3}$ of deuterium.

Instead, $236 \mathrm{~atm} \mathrm{~cm}^{3}$ were adsorbed. The barrier appears to be penetrable.

\section{DISCUSSION}

Our main concern in these experiments is with physical adsorption and barrier and bulk diffusion processes. The addition of a thin layer of titanium to an apparently occluded surface has the effect of providing an increase in the physical adsoprtion rate. The results obtained in experiment I (figure 2). indicate quite dramatically our ability to penetrate the inhibiting surface film. Based on the formation of $\mathrm{TiD}_{1.5}$, the 0.09 grams of titanium which was deposited on the chamber surface should have been completely used up in 73 minutes; instead it took a total of 1688 minutes. The reduction in the rate of change of system pressure with time at 100 minutes represencs a condition under which the leak rate of deuterium into the system is matched by the physical adsorption and diffusion of the deuterium into the substrate. The gradual decrease in the slope after 600 minutes indicates that diffusion through the barrier and into the bulk titanium is occurring quite readily.

Experiment II'was performed in order to determine if the physical adsorption rate was limiting the amount of deuterium diffusing into the bulk titanium. After curve $\equiv_{2}$ in figure 3 was measured, a period 
of 11 hours elapsed before the measurements for curves $\# 3$, 非, and 非 5 were made. The large change in slope between curve 非 and curves $\# 3$, 非, and $\mathbb{N}_{5}$ at $1 \times 10^{-6}$ torr indicates that the surface physical adsorption rate could have changed significantly during the 17hour period between the start of the measurement of curve $\#_{2} 2$ and curve 非. This result was verified by the deposition of another layer of titanium (same as for curve $\#_{2}$ ) and the admission of deuterium gas: Curve \#6 (figure 3) indicates that the surface film is again being penetrated and is not greatly limited by physical adsorption, nor does it appear to be diffusion limited. The 0.08 grams of titanium deposited before the measurement of curve 非 6 should have maintained the system pressure for on $1 y$ about 67 minutes. The fact that it lasted'for 247 minutes indicates that a previously deposited sublayer of titanium was being utilized and that indeed curves 1 3, 非, and 非 5 were physicaladsorption limited.

The results of experiment III indicate that a 5-minute deposition of titanium is not sufficient to make most of the titanium sublayer accessible. The chamber is cylindrical $(68.5 \mathrm{~cm}$ in length by $45.6 \mathrm{~cm}$ in diameter) and a monolayer should be formed in about 5 seconds. In practice it would seem from the results of figure 4 that in order to be totaliy effective in our chamber, a thickness of about 180 monolayers (15-minute sublimation) would be required. This does not seem unreasonalie since the source 1 s not isotropic nor is it symmetrically positioned in the chamber, and much more surface is available for sublimation than the chamber geometry would indicate. The irregularity 
of the surface can be seen in figure 6 which shows a typical uneven titanium deposition. The curves for the 15, 30, and 60-minute sublimation runs also show a reversal in slope which indicates a limited amount of bulk titanium available. Verification of this is shown in

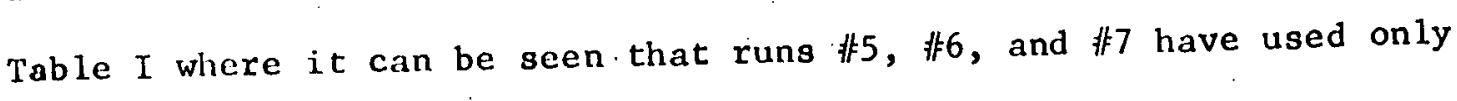

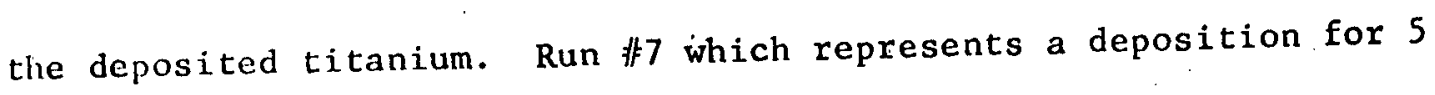
minutes on a surface with no bulk reserve lasted for about 60 minutes which is in good agreement with calculations.

Experiment IV was supposed to indicate that oxygen present in the system could indeed be responsible for the formation of an inhibiting film. A 60-minute layer (1 gram) of titanium was deposited to supply the source of bulk titanium and an amount of oxygen was admitted which should have covered the entire surface of the sublimator chamber with at least a monolayer. As can be seen from figure 5, at first it was not possible to penetrate the inhibiting oxide film. Only after deposition of a newly formed thin film did the bulk titanium become available. The important result of this experiment is that we were able to penetrate an oxide barrier with a thin layer of titanium after the surface was closed: While these results do not prove conclusively that oxygen is responsible for the formation of the inhibiting film in the normal operation of our system, it does seem a likely candidate since the decomposition of water vapor in the vacuum system supplies a continuous source of oxygen.

It shoyld be made clear that the primary purpose of this vacuum system was not to conduct research into the penetration of Inhibiting 
films on ititanium substrates. The system was not designed to meet this function and, as a result, the accuracy of some of the measurements leaves something to be desired; however, the overall results are valid and suggest many interesting possibilities for incorporating this concept in the design of sputter ion pumps and the formation of titanium tritide targets.

SUMMARY

We have shown that it is possible to gain access to sublayers of uncombined titanium in spite of an inhibiting film (such as oxygen) on the surface. While we have not demonstrated that the film must be an oxide, we have shown that if it is, then it can be penetrated. Although most of the work presented here was directed toward more effective utilization of titanium in bulk sublimation pumping for small positive-ion accelerators, these results should be of considerable interest to others concerned with hydrogen pumping in general and the problems associated with inhibiting films. REFERENCES

1. R. Steinberg and D. L. Alger, "A New Pumping System for a 150 Kilovolt Neutron Generator to Reduce the Present Tritium Hazard" (BRH/DEP73-2, 1972).

2. V. A. Livanov, A. A. Bukhanova, and B. A. Kolachev, "Hydrogen in Titanium" (Davey, New York, 1965).

3. V. A. Livanov, A. A Buchanova, and B. A. Kolachev, in Ref. 2, p. 38.

1. V. I. Yavoiskii and G. I. Batalin, Trudy Nauch.-Tekh. Obshchestra Chermi Met., 4, 74: (1955).

5. D. N. Williams, B. G. Koehl, and E. S Bartlett, Less-Common Metals, 19, 385 (1969).

6. R. Steinberg and D. L. Alger, Vacuum, 20, 521 (1970). 


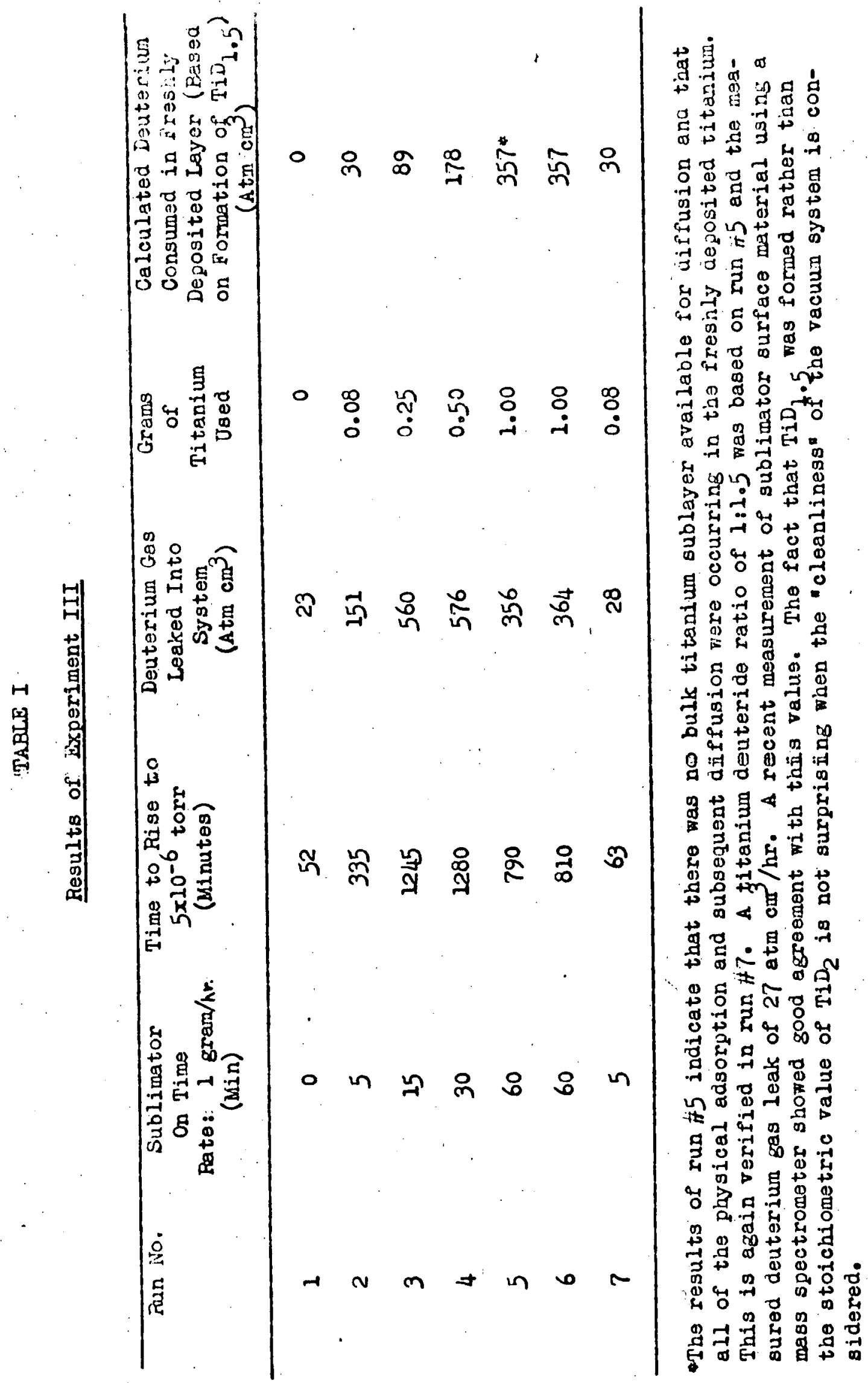




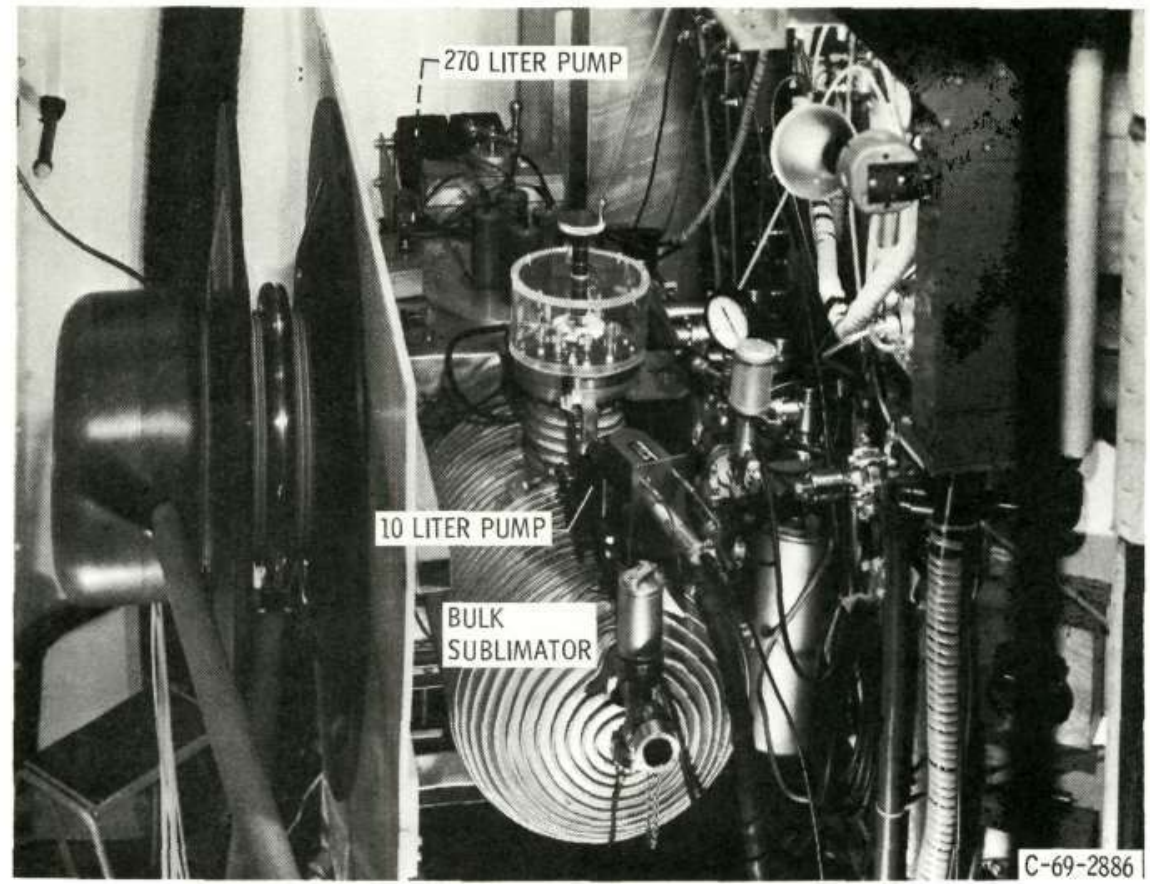

\begin{tabular}{l}
$N$ \\
\multirow{2}{*}{} \\
\multirow{1}{1}{} \\
되
\end{tabular}

Figure 1. - 300 Kilovolt ion accelerator which served as vacuum chamber for all the measurements.

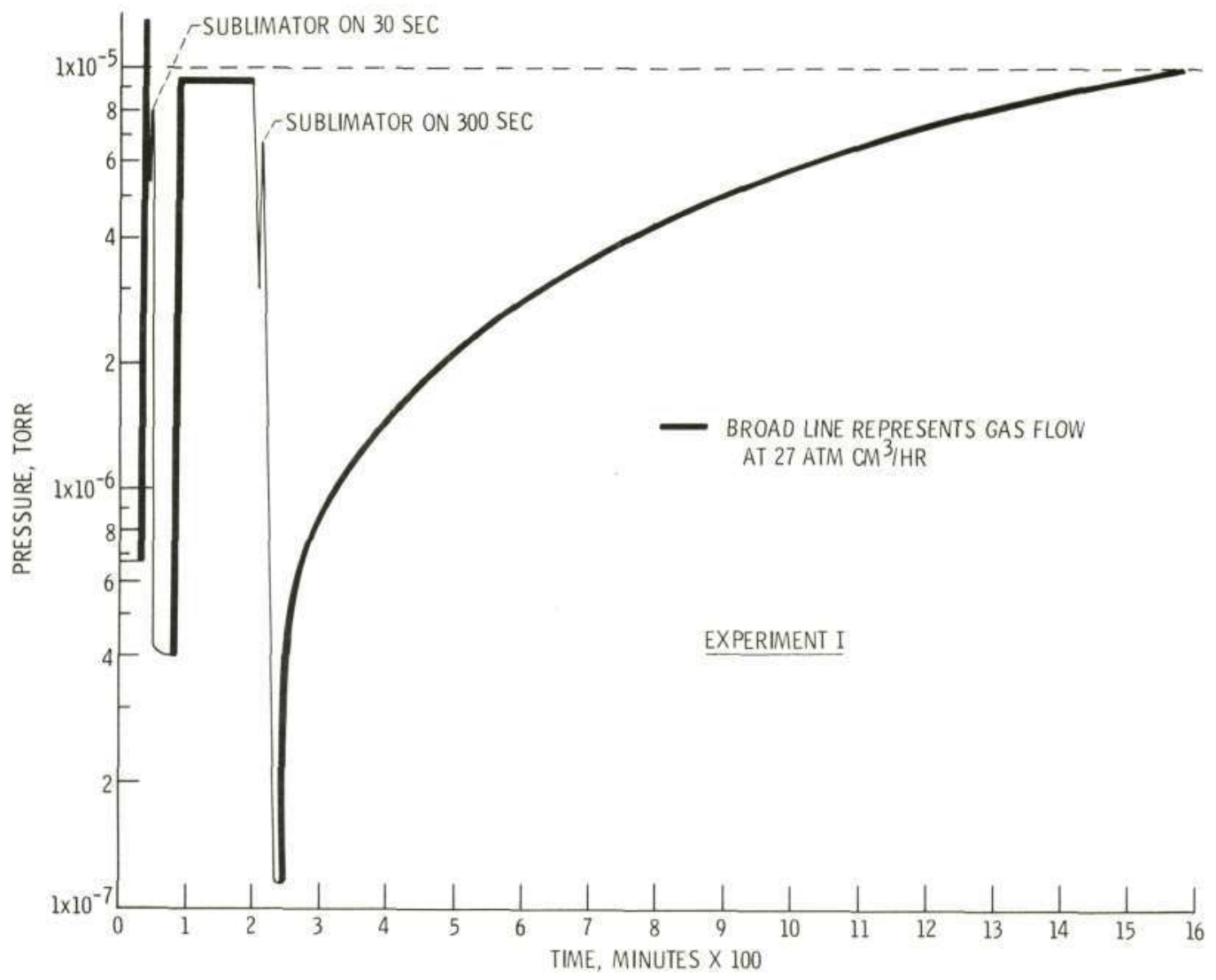

Figure 2. - Shows a plot of the variation of system pressure for various deuterium gas load conditions and dem onstrates ability to penetrate the inhibiting film. 


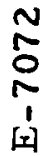

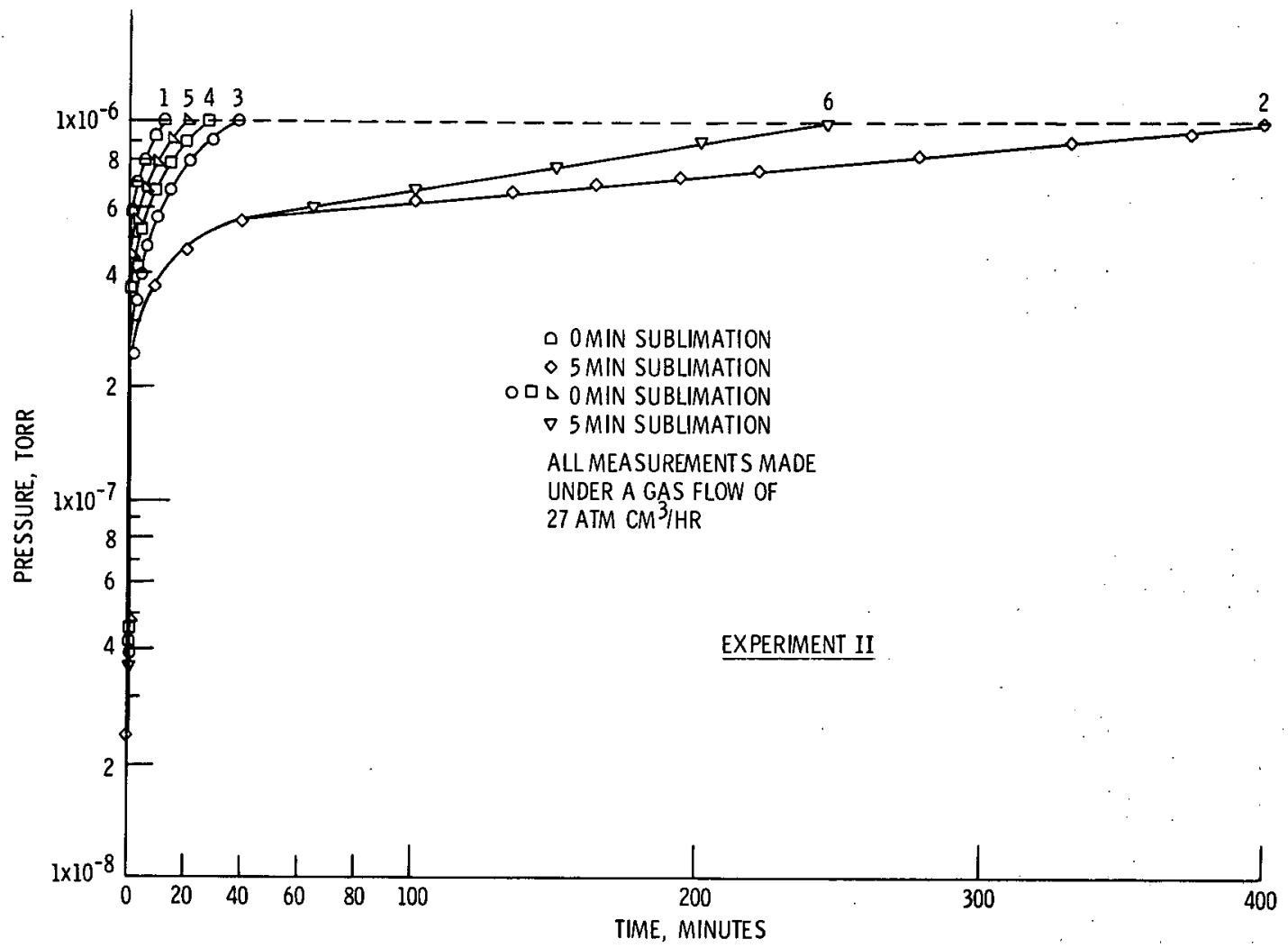

Figure 3. - Shows the effect of physical adsorption on the system pressure under a deuterium gas load.

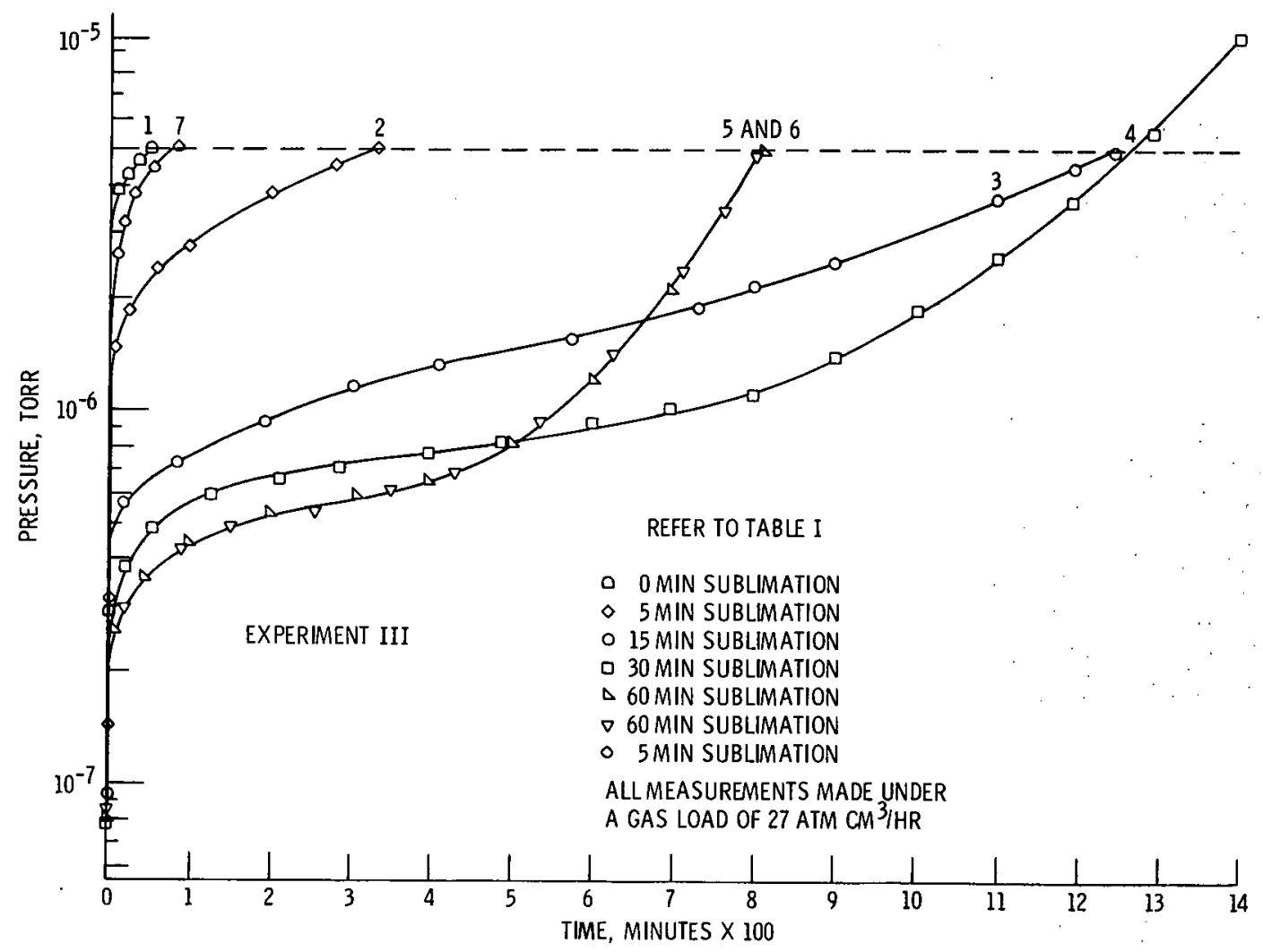

Figure 4. - Shows the effect of the variation in sublimation time on system pressure and indicates the need for multim onolayer deposition to penetrate inhibiting film. 


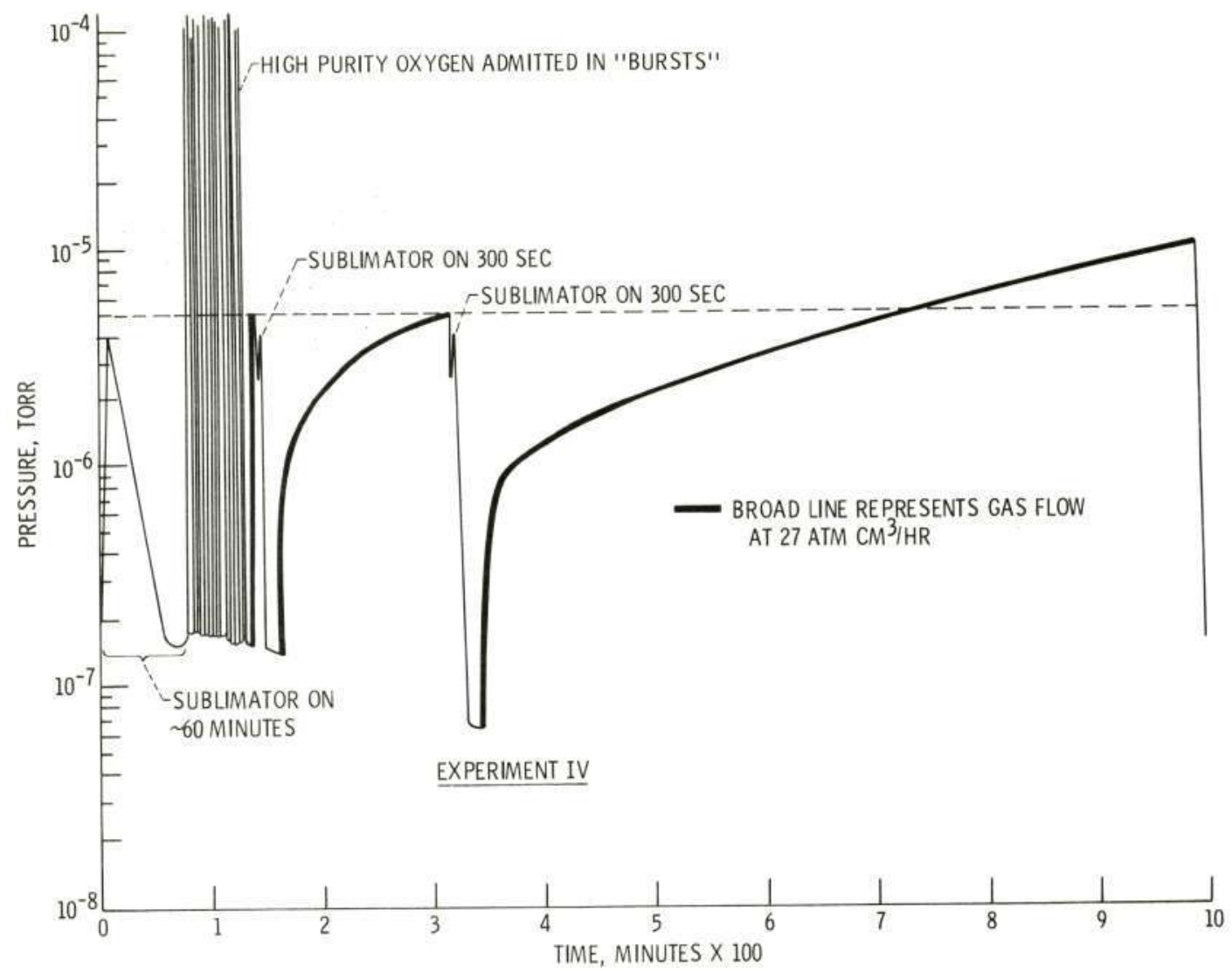

Figure 5. - Shows the effect of an oxide barrier on system pressure (under gas load) and dem onstrates the ability to penetrate this barrier.

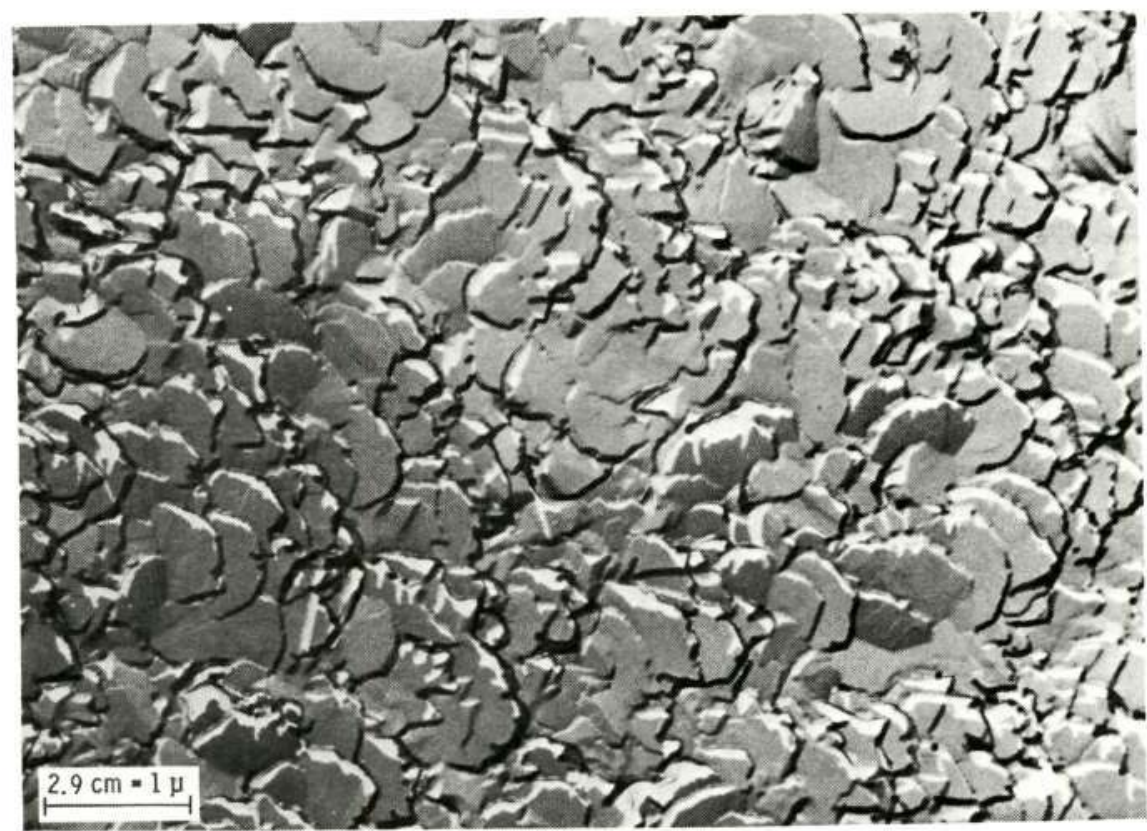

Figure 6. - Magnified view of a typical sublimated surface. 